\title{
SIMULATION OF SORTING SEDIMENTATION IN THE CHANNEL OF HUANGHUA HARBOR BY USING 3D MULTI-SIZED SEDIMENT TRANSPORT MODEL OF EFDC
}

\author{
Qing-He Zhang ${ }^{1}$, Feng Tan $^{1}$, Tao Han ${ }^{1}$, Xiao-Yuan Wang ${ }^{2}$, Zhi-Qiang Hou ${ }^{3}$, Hua Yang ${ }^{3}$ \\ Huanghua Harbor, located in the south-west coast of Bohai Bay, China, has frequently encountered severe channel \\ siltation with sorting sedimentation along the channel during storm events since its construction. For prediction of \\ channel siltation, a 3D numerical model of multi-fraction sediment transport based on the coupling of modified EFDC \\ model and SWAN model is developed to investigate the sediment transport. It is shown from simulated results that the \\ sorted sedimentation in the channel was well simulated in storm events, and the high sediment concentration near sea \\ bed for silty coast during storm process can also be basically reflected by the model.
}

Keywords: EFDC model; SWAN model; Sorting Sedimentation; multi-fraction sediment; sediment concentration

\section{INTRODUCTION}

Huanghua harbor is a coal-export harbor, located at Bohai Bay, China. It is sited on a typical silty coast with very mild slope, and the medium diameter $\left(d_{50}\right)$ on the surface layer of the beach bed is 0.0044-0.0689mm. Huanghua harbor has frequently encountered severe channel siltation during storm events since it was constructed. Extensive researches have been carried out to explore the mechanism of sediment transport and channel siltation of Huanghua Harbor. Zhang et al. (2006) and Zhao (2006) developed 2D and 3D numerical models respectively to investigate the sediment transport and channel siltation of Huanghua Harbor in storm events. Yan (2008) developed the vertical concentration profile expressions with high concentration near sea bed for silt suspension due to waves or combined waves and current.

However, the properties of sorting sedimentation along the channel were not fully described in the previous models. Therefore, the objective of the present paper is to develop a numerical model to simulate the sorting sedimentation along the channel. For typical silty coasts interested here, the sediment is mainly suspended by wind waves and transported by current, so the combined wavecurrent action is very important. In shallow water, the wave breaking also plays important roles in the vertical concentration distribution of suspended sediment. In addition, the high concentration layer near the sea bed plays a significant role in the severe channel siltation. Therefore, for prediction of channel siltation of Huanghua Harbor on silty coast, a sediment transport model incorporating the above effects is needed. A 3D numerical model for multi-fraction sediment transport based on the coupling of modified EFDC model and SWAN model is developed and applied in the present paper to investigate nearshore sorting sedimentation and the channel siltation process of Huanghua Harbor under the combined action of wind, waves and current.

\section{NUMERICAL MODELS}

\section{Modified EFDC Model}

The Environmental Fluid Dynamics Code (EFDC) is a public domain surface water modeling system incorporating fully integrated hydrodynamics, originally developed by John Hamrick at VIMS and presently maintained by Tetra Tech, Inc. The EFDC model includes turbulence closure model and can simulate wave boundary layers, wave-induced currents and combined wave-current bottom shear stress with multiple size class cohesive and non-cohesive sediment, and it is coupled with spectral wave model for wave induced re-suspension, but it doesn't take the wave breaking effect into consideration.

The governing equations for the EFDC hydrodynamic model equations are given below.

The momentum equation is:

${ }^{1}$ School of Civil Engineering, Tianjin University \& Key Laboratory of Harbor and Ocean Engineering (Tianjin University), Ministry of Education, Tianjin, 300072, P. R. China

${ }^{2}$ China Communication Planning and Design Institute for Waterway Transportation, Beijing, 100010, P. R. China

${ }^{3}$ Tianjin Research Institute of Water Transport Engineering, Ministry of Transport, Tianjin, 300456, P. R. China 


$$
\begin{gathered}
\frac{\partial(m H u)}{\partial t}+\frac{\partial\left(m_{y} H u u\right)}{\partial x}+\frac{\partial\left(m_{x} H v u\right)}{\partial y}+\frac{\partial(m w u)}{\partial z}-\left(m f+v \frac{\partial m_{y}}{\partial x}-u \frac{\partial m_{x}}{\partial y}\right) H v \\
=-m_{y} H \frac{\partial(g \zeta+p)}{\partial x}-m_{y}\left(\frac{\partial h}{\partial x}-z \frac{\partial H}{\partial x}\right) \frac{\partial p}{\partial z}+\frac{\partial}{\partial z}\left(m \frac{1}{H} A_{v} \frac{\partial u}{\partial z}\right)+Q_{u} \\
\frac{\partial(m H v)}{\partial t}+\frac{\partial\left(m_{y} H u v\right)}{\partial x}+\frac{\partial\left(m_{x} H v v\right)}{\partial y}+\frac{\partial(m w v)}{\partial z}+\left(m f+v \frac{\partial m_{y}}{\partial x}-u \frac{\partial m_{x}}{\partial y}\right) H u \\
=-m_{x} H \frac{\partial(g \zeta+p)}{\partial y}-m_{x}\left(\frac{\partial h}{\partial y}-z \frac{\partial H}{\partial y}\right) \frac{\partial p}{\partial z}+\frac{\partial}{\partial z}\left(m \frac{1}{H} A_{v} \frac{\partial v}{\partial z}\right)+Q_{v} \\
\frac{\partial p}{\partial z}=-g H \frac{\rho-\rho_{0}}{\rho_{0}}=-g H b
\end{gathered}
$$

The continuity equation is:

$$
\frac{\partial(m \zeta)}{\partial t}+\frac{\partial\left(m_{y} H u\right)}{\partial x}+\frac{\partial\left(m_{x} H v\right)}{\partial y}+\frac{\partial(m w)}{\partial z}=Q_{H}
$$

Where $h$ is the mean water depth; $H$ is the wave height; $u, v, w$ are the velocities in the direction of $\mathrm{x}, \mathrm{y}$ and z coordinates; $\zeta$ is the free-water level; $m=m_{x} m_{y}, m_{x}$ and $m_{y}$ are the transformation scale factors in horizontal coordinates.

The Mellor-Yamada Level 2.5 turbulence closure model (Mellor and Yamada 1982) is applied to solve diverse problems in EFDC, and parameters are determined by the following formulas:

$$
\left\{\begin{array}{l}
A_{V}=\phi_{V} A_{0} q l=\left(1+36 R_{q}\right)^{-1}\left(1+6 R_{q}\right)^{-1}\left(1+8 R_{q}\right) A_{0} q l \\
A_{B}=\phi_{B} K_{0} q l=\left(1+36 R_{q}\right)^{-1} K_{0} q l \\
R_{q}=-\frac{g H \partial_{z} b}{q^{2}} \frac{l^{2}}{H^{2}}
\end{array}\right.
$$

Where $q$ is the turbulence intensity; $l$ is the turbulence mixing-length; $R_{q}$ is the Richardson number; $b$ is the density gradient; $\phi_{A}$ and $\phi_{B}$ are stability functions that depend on $R_{q}, A_{0}$ and $K_{0}$ are constant, usually 0.4 and 0.5 respectively.

Only suspended sediment transport is considered in EFDC model. The governing equation for fine sediment transport is three-dimensional convection-diffusion equation ignoring the horizontal diffusion of sediment, which is given as below:

$$
\begin{gathered}
\frac{\partial\left(m_{x} m_{y} H S_{j}\right)}{\partial t}+\frac{\partial\left(m_{y} H u S_{j}\right)}{\partial x}+\frac{\partial\left(m_{x} H v S_{j}\right)}{\partial y}+\frac{\partial\left(m_{x} m_{y} w S_{j}\right)}{\partial z} \\
-\frac{\partial\left(m_{x} m_{y} w_{s j} S_{j}\right)}{\partial z}=\frac{\partial}{\partial z}\left(m_{x} m_{y} \frac{K_{V}}{H} \frac{\partial S_{j}}{\partial z}\right)+Q_{s j}^{E}+Q_{s j}^{I}
\end{gathered}
$$

Where $S_{j}$ is the sediment concentration of the $j$ th fraction.

In nearshore zones, the wave breaking plays an important role on vertical concentration distribution and sediment transport, so the EFDC model in this paper is modified by incorporating the wave breaking effect by using the sediment diffusivity due to wave breaking presented by van Rijn (2007). The vertical diffusion coefficient of sediment suspension considering the wave breaking effect can be seen in Eq.(7-11). 


$$
\begin{gathered}
\varepsilon_{w}= \begin{cases}\varepsilon_{w, \text { bed }}, & 0 \leq z<\delta_{s} \\
\varepsilon_{w, b e d}+\left(\varepsilon_{w, \max }-\varepsilon_{w, \text { bed }}\right)\left(\frac{z-\delta_{s}}{0.5 h-\delta_{s}}\right), & \delta_{s} \leq z<0.5 h \\
\varepsilon_{w, \max }, & z \geq 0.5 h\end{cases} \\
\varepsilon_{c w}= \begin{cases}A_{o} q_{w c} \kappa z, \quad z_{o} \leq z<\delta_{w c} \\
A_{o} q_{w c} \kappa \delta_{w}, \delta_{w c} \leq z<\frac{q_{w c}}{q_{c}} \delta_{w c} \\
{\left[\left(A_{o} q_{c} k z\right)^{2}+\left(\varepsilon_{w, b e d}+\left(\varepsilon_{w, \max }-\varepsilon_{w, b e d}\right)\left(\frac{z-\delta}{0.5 h-\delta}\right)\right)^{2}\right]^{0.5}, \frac{q_{w c}}{q_{c}} \delta_{w c} \leq z<0.5 h} \\
{\left[\left(A_{o} q_{c} k z\right)^{2}+\left(0.035 \gamma_{b r} \frac{h H_{s}}{T}\right)^{2}\right]^{2}, z \geq 0.5 h}\end{cases}
\end{gathered}
$$

Where

$$
\begin{gathered}
\varepsilon_{w, \text { bed }}=0.018 \beta_{w} \delta_{s} u_{m} \\
\varepsilon_{w, \max }=0.035 \gamma_{b r} \frac{h H_{s}}{T} \\
\gamma_{b r}= \begin{cases}1+\left(\frac{H}{h}-0.4\right)^{0.5} & \frac{H}{h}>0.4 \\
1 & \frac{H}{h} \leq 0.4\end{cases}
\end{gathered}
$$

In addition, more factors such as wind shear stress on the surface, dry and wetting in the shallow water, bed sediment transport, settling velocity (van Rijn 2007), and reference concentration (van Rijn 2007) are also incorporated in this model.

\section{SWAN Model}

SWAN model is a wind-wave model based on the action density balance equation. The wave process during storm was simulated by SWAN model successively. The detailed SWAN model can be seen in Booij (1999) and would not be given here.

\section{Coupling between EFDC and SWAN Models}

Numerical simulation covers three levels of nested computational domains of increasing resolution: ocean (Bohai), regional (Bohai Bay) and coastal (Huanghua). The SWAN and EFDC models are coupled through data exchange in regional and coastal domains respectively, in which EFDC provides SWAN with time series of water elevation and current velocity, and SWAN supplies EFDC with arrays of radiation stress (see Fig. 1). The multi-sized sediment transport and channel siltation are only calculated in the coastal domain by EFDC.

\section{Verification}

The hydrodynamic and sediment model has been calibrated with field observations and the results would be given here.

The simulated sediment concentration profiles with and without breaking effect compared with the measured sediment concentration from Han et al. (2006) are shown in Fig. 2.

It can be seen from the figure that the EFDC model incorporating the wave breaking effect is more likely to predict the actual situation, and it is reliable to apply the modified EFDC model to simulate the sediment transport. 


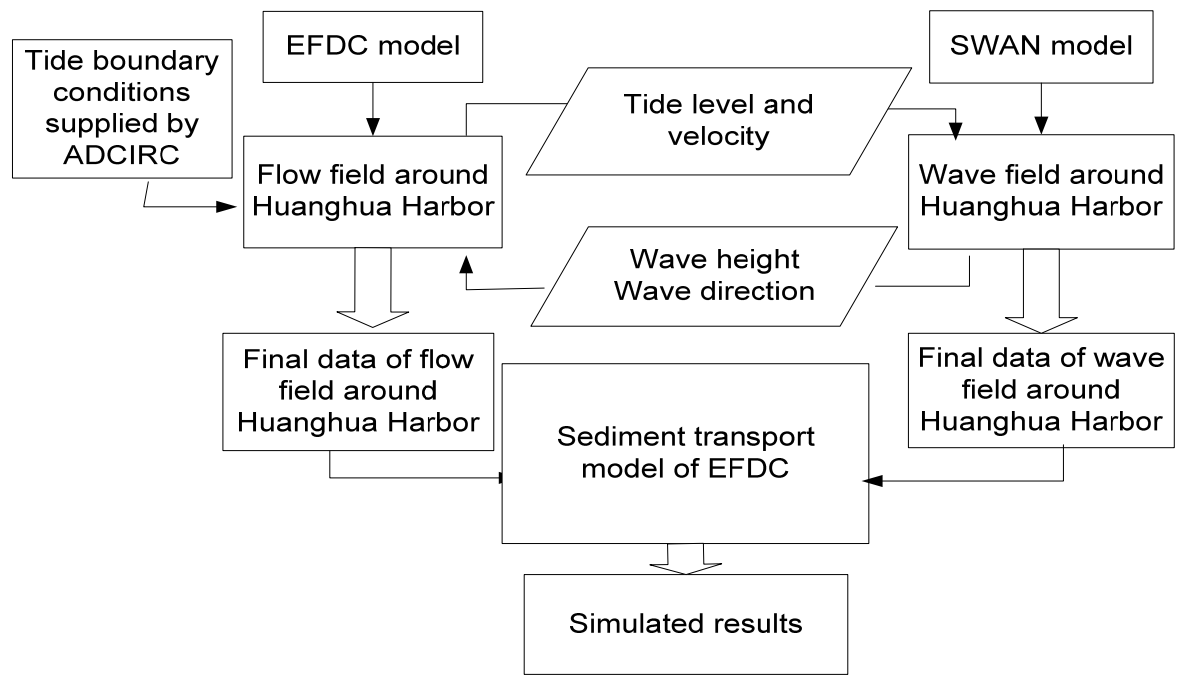

Figure 1. Computational procedures of sediment transport and channel siltation.
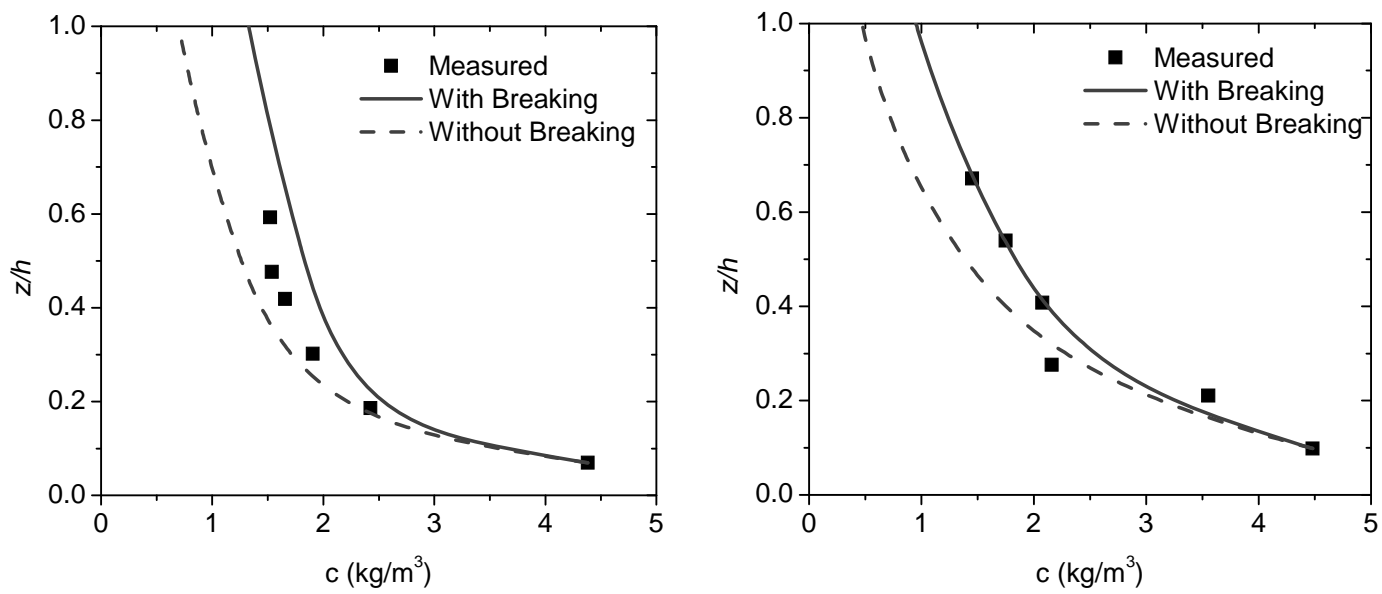

Figure 2. Comparison of simulated sediment concentration profiles and measured data.

In order to calibrate the high concentration layer near seabed, the sediment concentration profiles due to combined waves and current for multi-sized sediment simulated by the modified model are compared with the experimental values by van Rijn, et al. (1993), and the results are shown in Fig. 3.
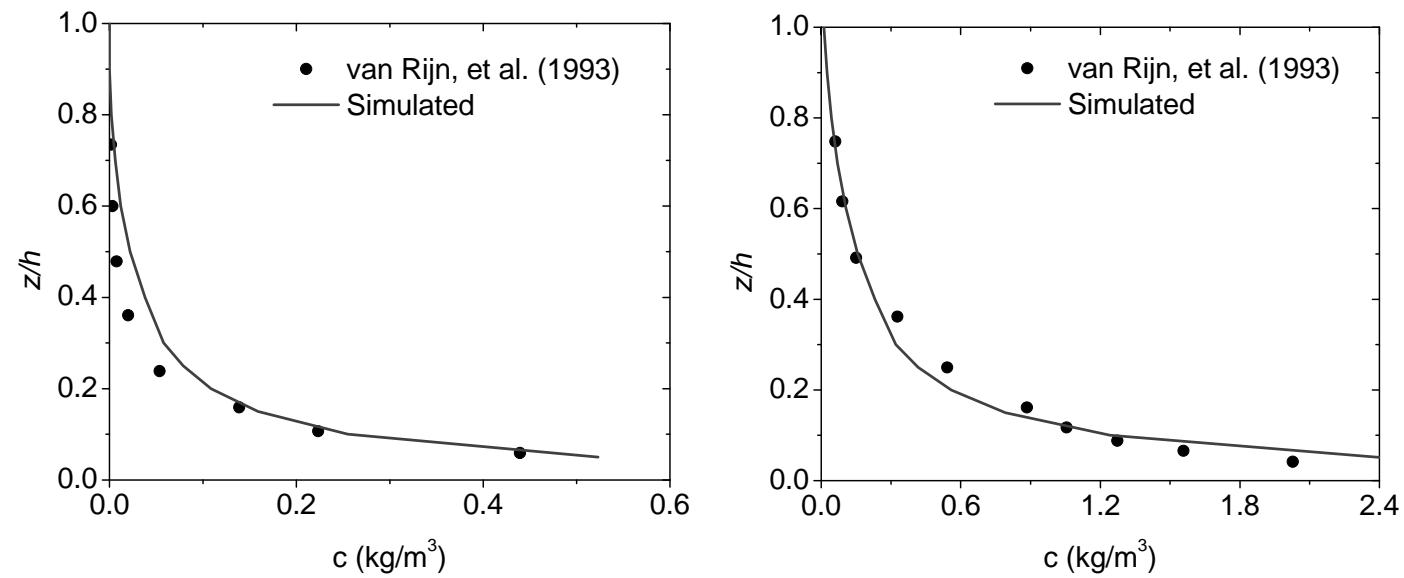

Figure 3. Comparison of sediment concentration predicted by the coupled model and the experimental data from van Rijn, et al. (1993). 
The simulated sediment concentration match very well with the experimental values from van Rijn, et al. which demonstrates that the modified EFDC model is able to predict high concentration layer near seabed correctly to a certain extent.

\section{MODEL APPLICATION FOR HUANGHUA HARBOR DURING STORM EVENTS}

\section{Model Setup}

The sediment was divided by four fractions with the particle size of $0.004 \mathrm{~mm}, 0.01 \mathrm{~mm}, 0.03 \mathrm{~mm}$ and $0.07 \mathrm{~mm}$, and the settling velocities $0.00045 \mathrm{~m} / \mathrm{s}, 0.0006 \mathrm{~m} / \mathrm{s}, 0.0011 \mathrm{~m} / \mathrm{s}, 0.0077 \mathrm{~m} / \mathrm{s}$ respectively. The distribution of $d_{50}$ in the computational domain is shown in Fig. 4.

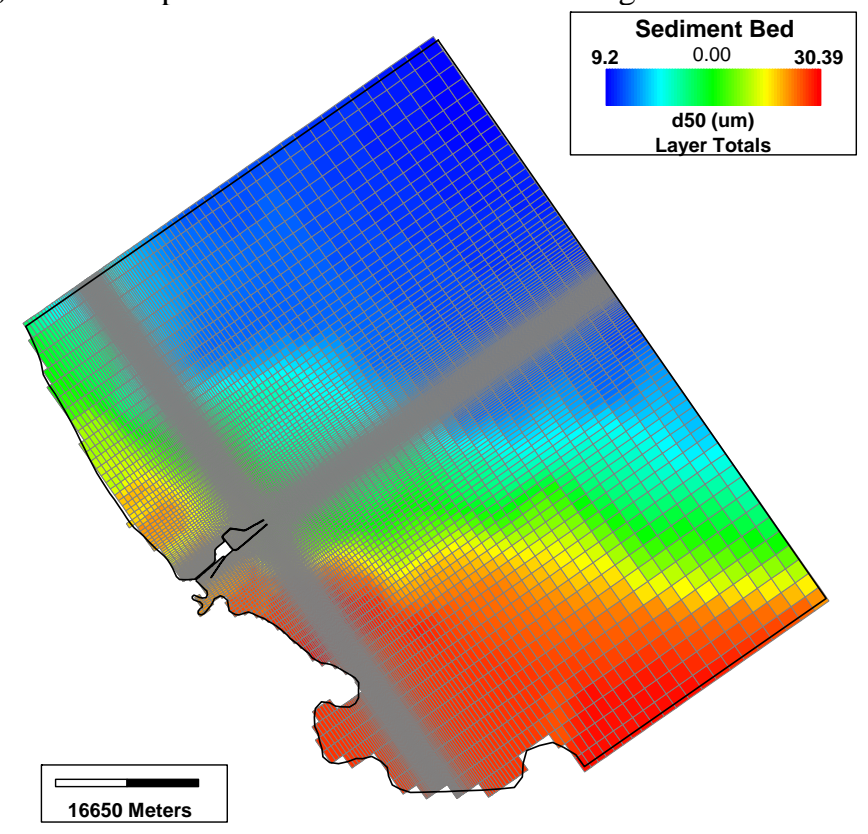

Figure 4. Distribution of $d_{50}$ in the computational domain.

Two storm events, which occurred on October 10, 2003 and March 10, 2006 respectively, were chosen to simulate the sediment transport and channel siltation. The October 10, 2003 storm event represents the situation before breakwater extension while the March 10, 2006 storm event represents the situation after breakwater extension. Layout of breakwaters at Huanghua Harbor before and after breakwater extension is shown in Fig. 5.

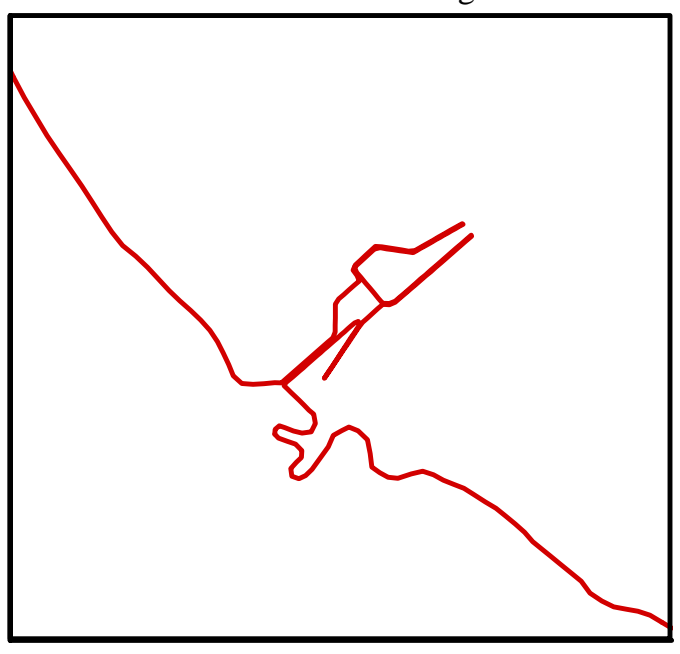

(a)Before breakwater extension

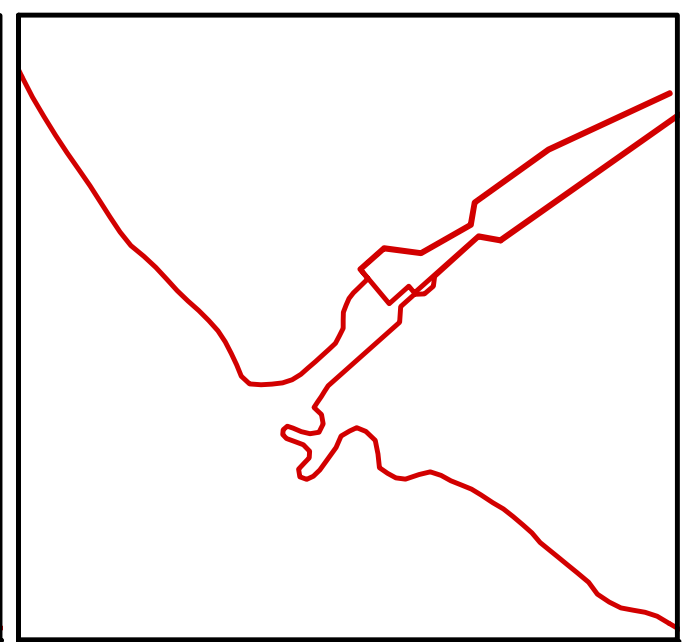

(b) After breakwater extension

Figure 5. Sketch of breakwaters at Huanghua Harbor. 
The sampling points used for wave, hydrodynamic and sediment analysis are shown in Fig. 6. Point A is used to demonstrate the wave process at $300 \mathrm{~m}$ north of channel $\mathrm{W} 10+500$, point $\mathrm{B}$ is the tide station, which is used for testing the water elevation. Points $1 \# \sim 8 \#$ are used to extract suspended sediment distribution with and without wave breaking effects under different sea levels.

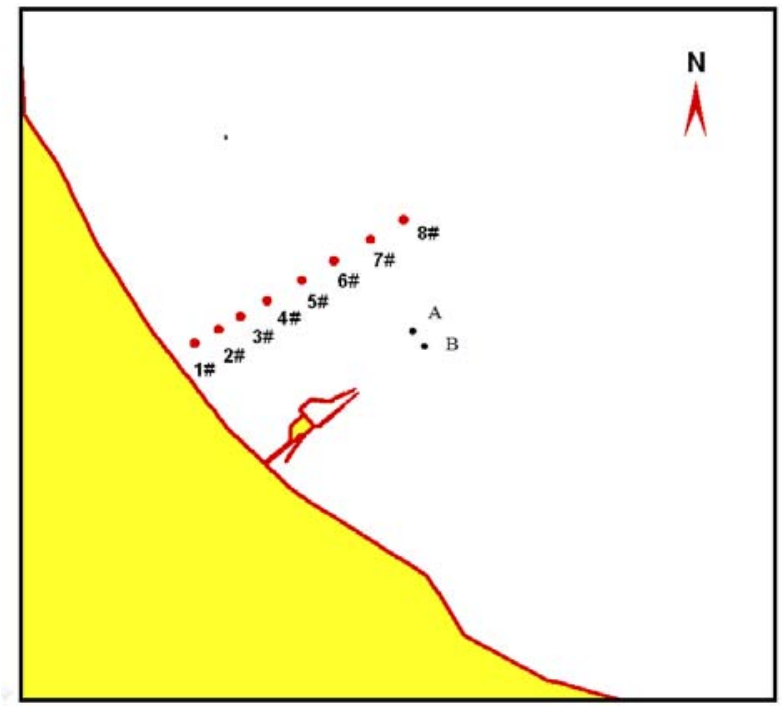

Figure 6. Sampling points used for wave, hydrodynamic and sediment analysis.

\section{Wave Simulation}

Fig. 7 - 8 show the wind process with simulated and measured wave height during October 10-12, 2003 and March 12-13, 2006 respectively. During the storm event in 2003, the total duration of wind above wind force 6 was 43 hours, and the one above wind force 8 was more than 27 hours, the maximum wind process in record. The wind mainly came from NE and ENE during the storm. During the storm event in 2006, the wind mainly came from north, and the total duration of wind above wind force 6 was 14 hours.
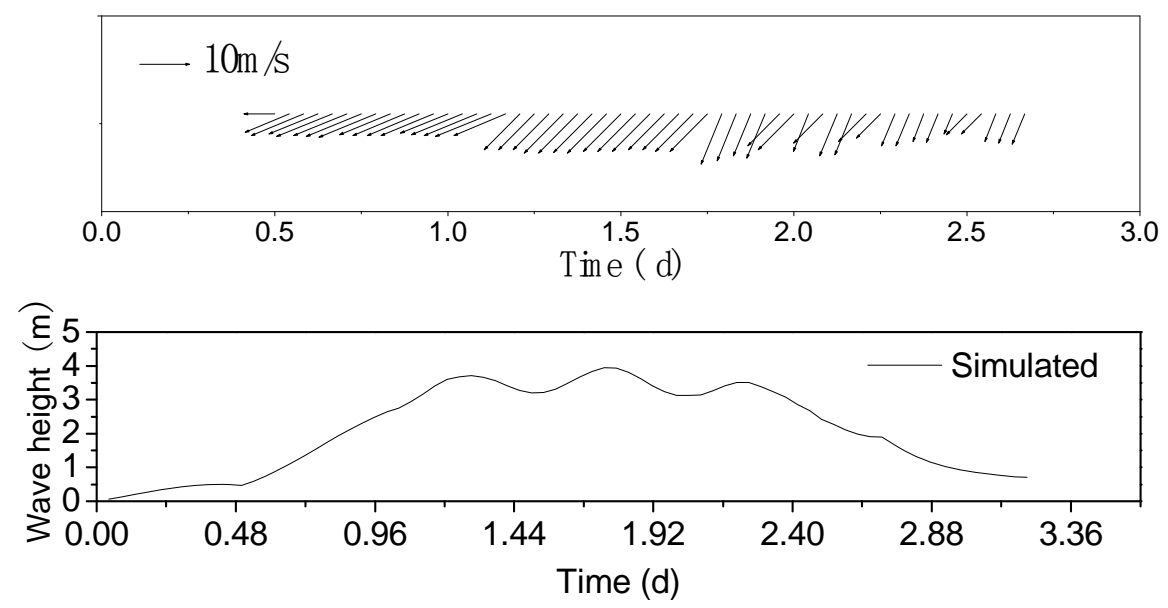

Figure 7. Wind speed and wave height during October 10-12, 2003 (0 means 0:00 October 10, 2003). 

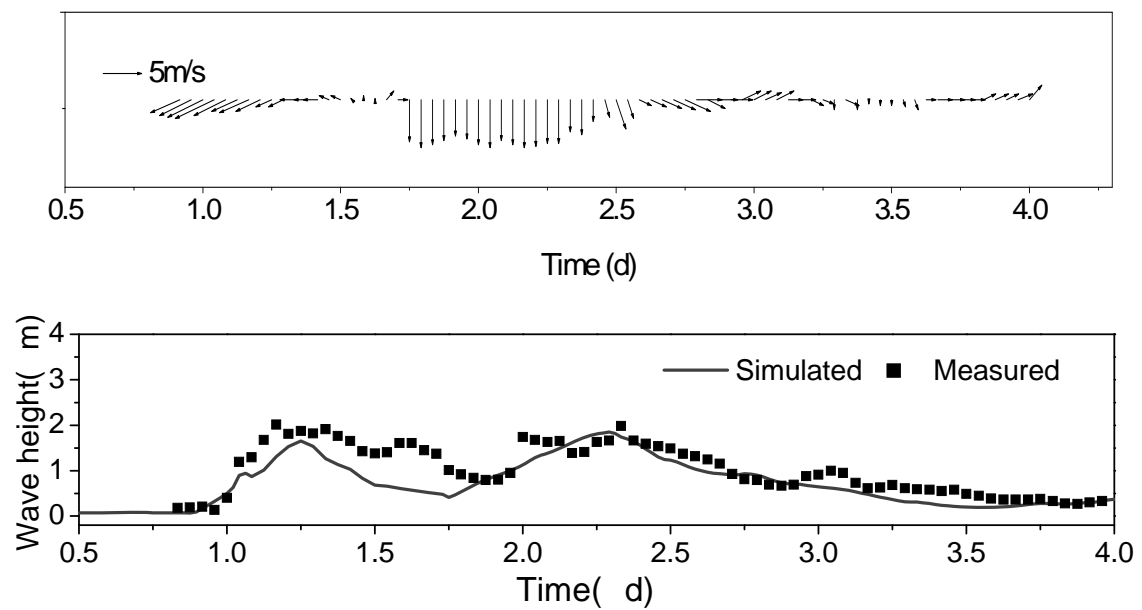

Figure 8. Wind speed and wave height during March 12-13, 2006 (0 means 0:00 March 10, 2006).

No measured data are collected during the storm event during October 10-12, 2003, so the wave height process in 2003 is given at the same position (Point A) as in 2006. It can be seen from the above figures that the wave model can basically reflect the wave height variation during the strong wind process.

\section{Hydrodynamic Simulation}

Fig. 9-10 show the comparison between the simulated water level and the measured data during October 10-12, 2003 and March 12-13, 2006. The simulated results agree with the measured data, and the storm surge process occurred during October 10-12, 2003 was well simulated.

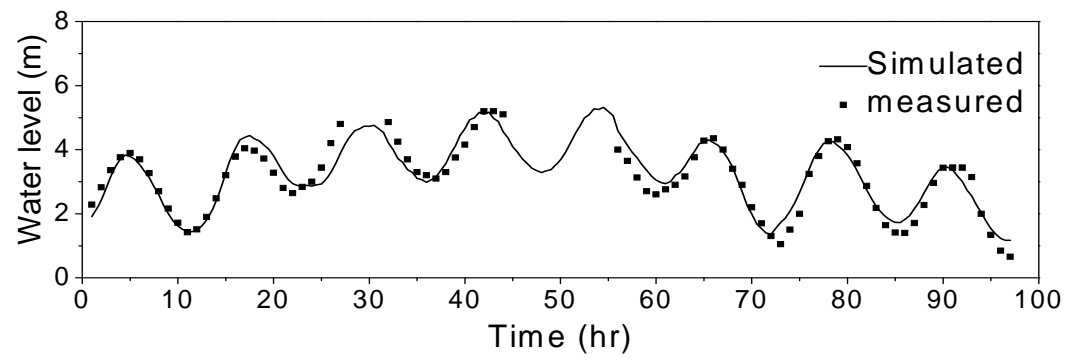

Figure 9. Water elevation during October 10-12, 2003 (0 means 0:00 October 10, 2003).

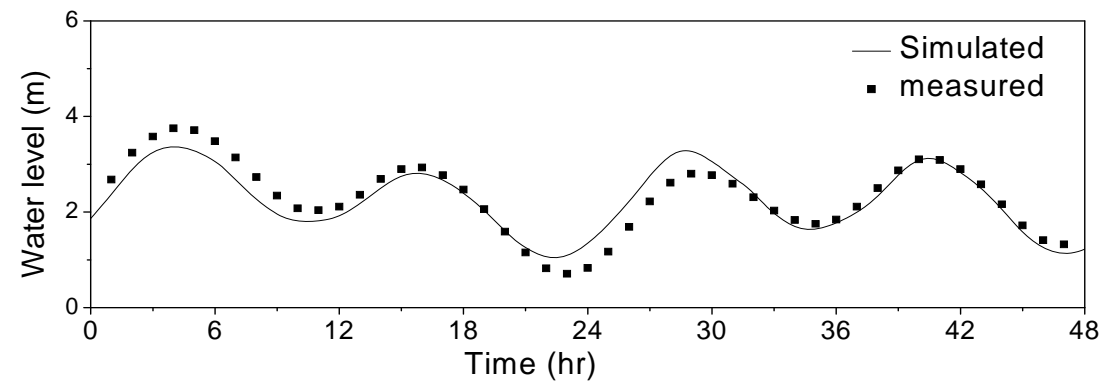

Figure 10. Water elevation during March 12-13, 2006 (0 means 0:00 March 10, 2006).

\section{Sediment Simulation}

The simulated results at eight sampling points (see Fig. 6), located at the north of the Huanghua Harbor with water depth from $-2 \mathrm{~m}$ to $-9 \mathrm{~m}$ at the mean sea level (From $0.4 \mathrm{~m}$ to $-6.6 \mathrm{~m}$ at the theoretical lowest sea level), were collected to show the sediment concentration distribution. Comparison of suspended sediment distribution with and without wave breaking effect at the highest tide level (08:20 October 11, 2003) and the lowest tide level (02:30 October 11, 2003) was carried out. 
From Fig. 11 and 12 we can see that the impact of wave breaking on suspended sediment distribution is remarkable in shallow water (Points $1 \# \sim 6 \#$ ), while not obvious in the deep water.

The simulated results demonstrate that the high concentration layer near seabed can be simulated well, and the 3-D sediment model incorporating the wave breaking effects is able to reasonably predict nearshore sediment transport .

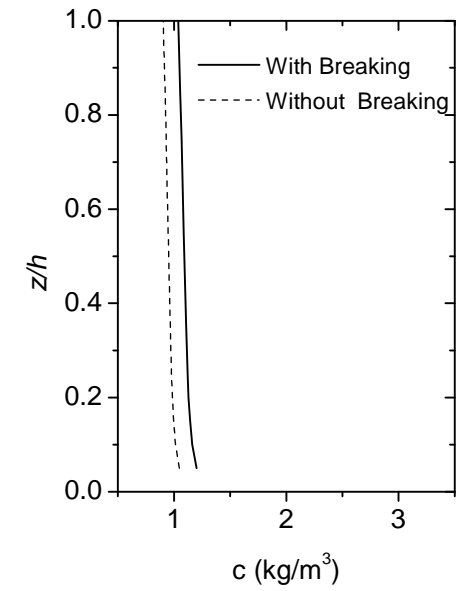

(1) 1\#

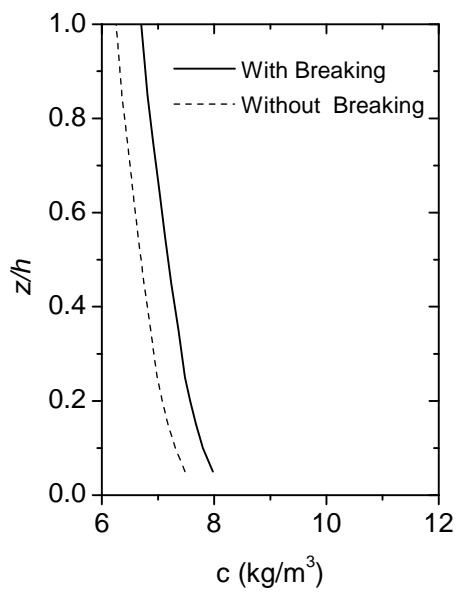

(4) $4 \#$

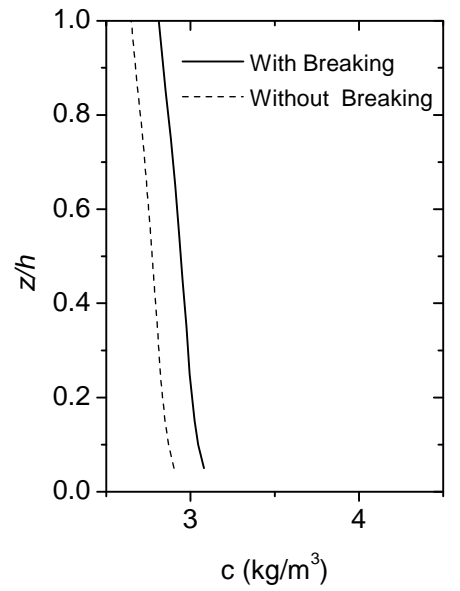

(2) $2 \#$

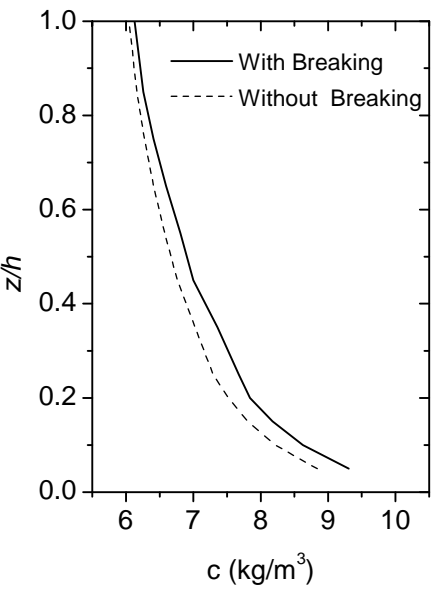

(5) $5 \#$

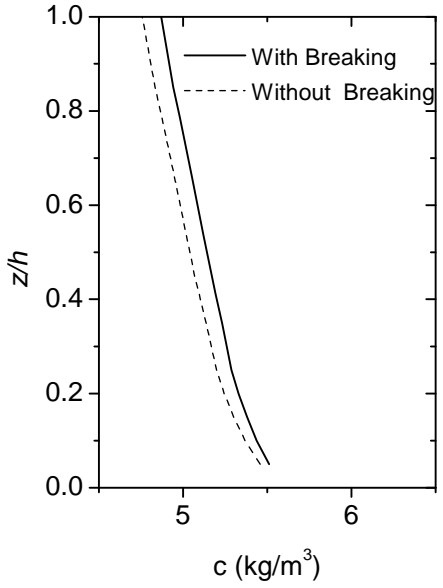

(3) 3\#

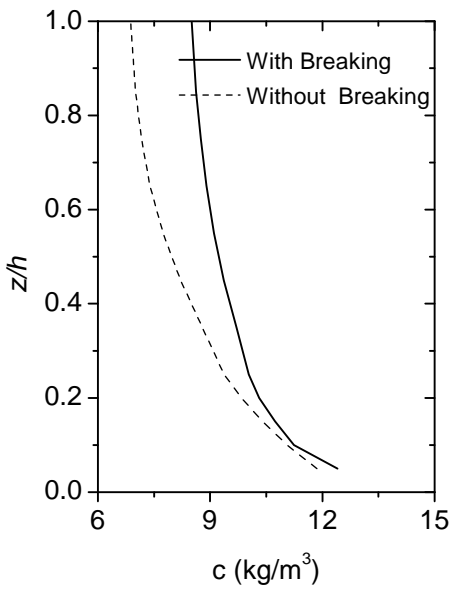

(6) $6 \#$

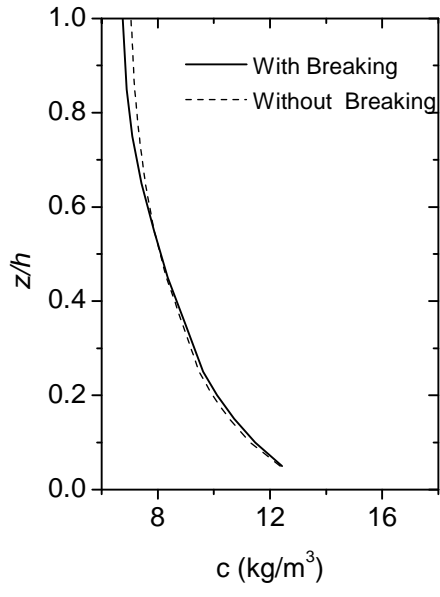

(7) $7 \#$

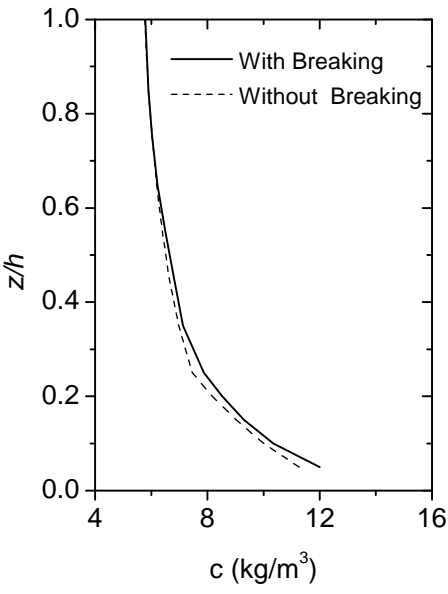

( 8) $8 \#$

Figure 11. Comparison of suspended sediment distribution with and without wave breaking effect at high tide level (Time: 08:20 October 11, 2003). 


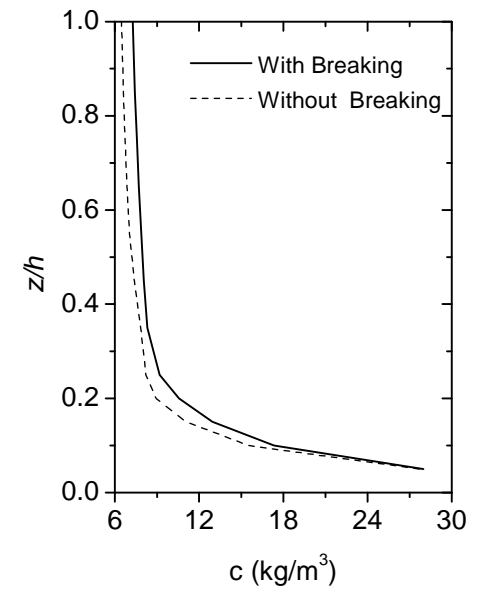

(1) $1 \#$

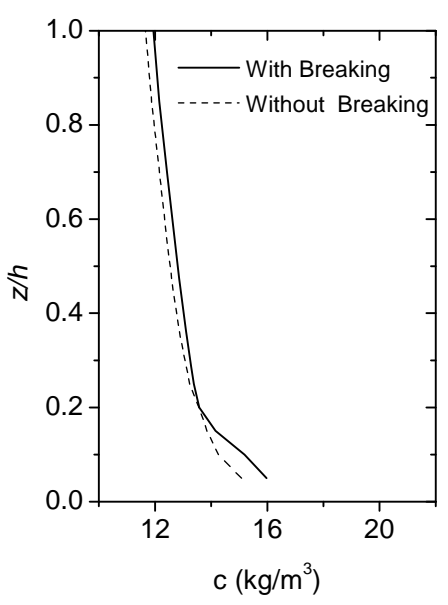

(4) $4 \#$

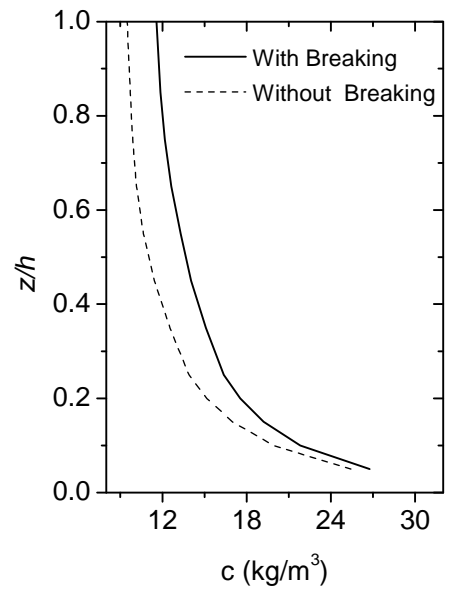

(2) $2 \#$

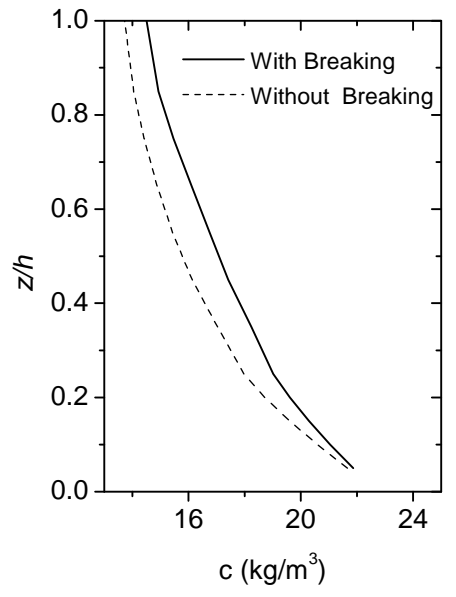

(5) $5 \#$

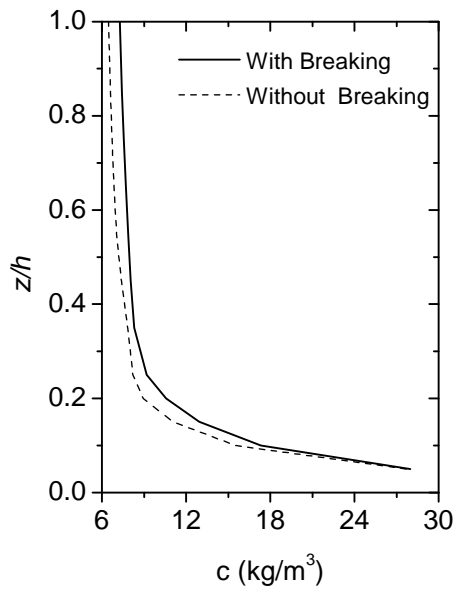

(3) $3 \#$

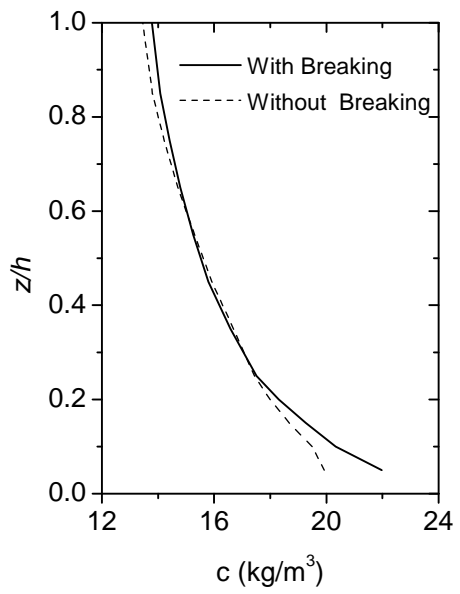

(6) $6 \#$

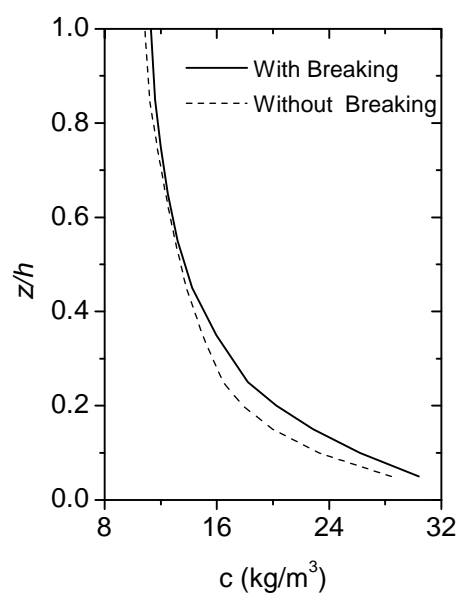

(7) $7 \#$

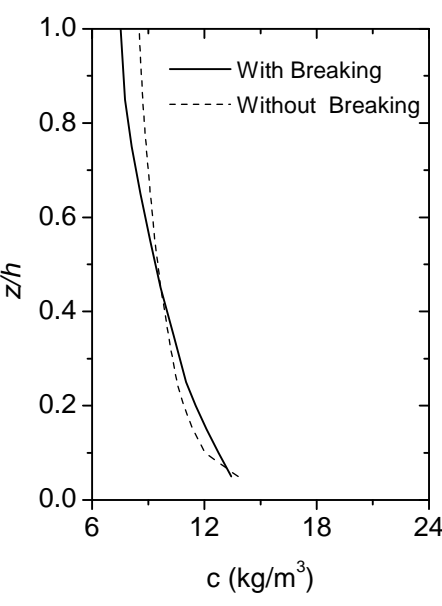

( 8) $8 \#$

Figure 12. Comparison of suspended sediment distribution with and without wave breaking effect at low tide level (Time: 02:30 October 11, 2003).

\section{Channel Siltation Simulation}

The comparison of calculated and measured siltation thickness and $d_{50}$ along the outer channel during October 10-12, 2003 and March 12-13, 2006 is shown in Fig. 13 and14.

Figure 13 shows that, before the breakwater extension in 2003, the channel siltation was very severe at $5 \mathrm{~km}-15 \mathrm{~km}$ to the harbor entrance and the maximum siltation thickness was up to $3.5 \mathrm{~m}$ at $8 \mathrm{~km}$ 
to the harbor entrance. The siltation depth was relatively small around the harbor entrance, and the siltation depth decreased obviously within the harbor entrance mainly due to the sheltering of breakwater. The simulated values are in consistent with the measured data.

Figure 14 shows that, after the breakwaters extension in 2006, the sediment deposition reduced obviously at the inside of sheltering area (within $10 \mathrm{~km}$ to harbor entrance), and severe channel deposition occurred about $15 \mathrm{~km}$ to the harbor entrance, which means that deposition conditions had remarkably been improved.

The simulated values are consistent with the measured data for both of the two storm events.

As for the $d_{50}$ distribution, in the storm event of October 10, 2003, the $d_{50}$ is larger at $0-15 \mathrm{~km}$ outside of the outer channel entrance, and relatively smaller inside of the channel entrance; while in the storm event of March 10, 2006, the proportion of the fine sediment increased, suggesting that the sorting sedimentation is obvious in Huanghua Harbor.
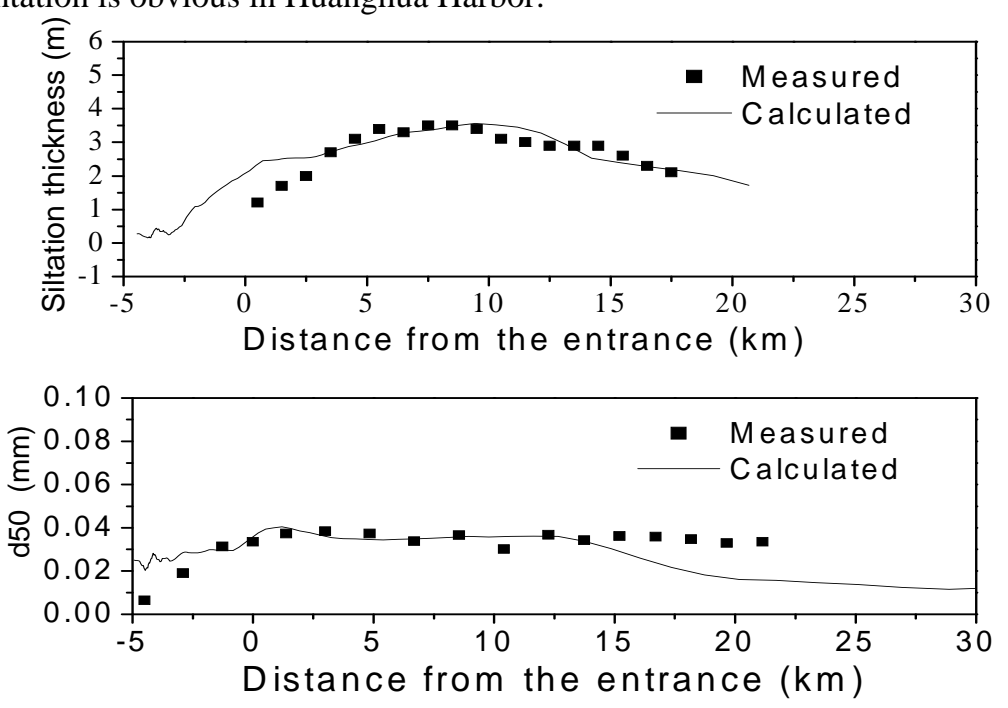

Figure 13. Calculated and measured siltation thickness and $d_{50}$ along channel in the storm event of October 10, 2003.
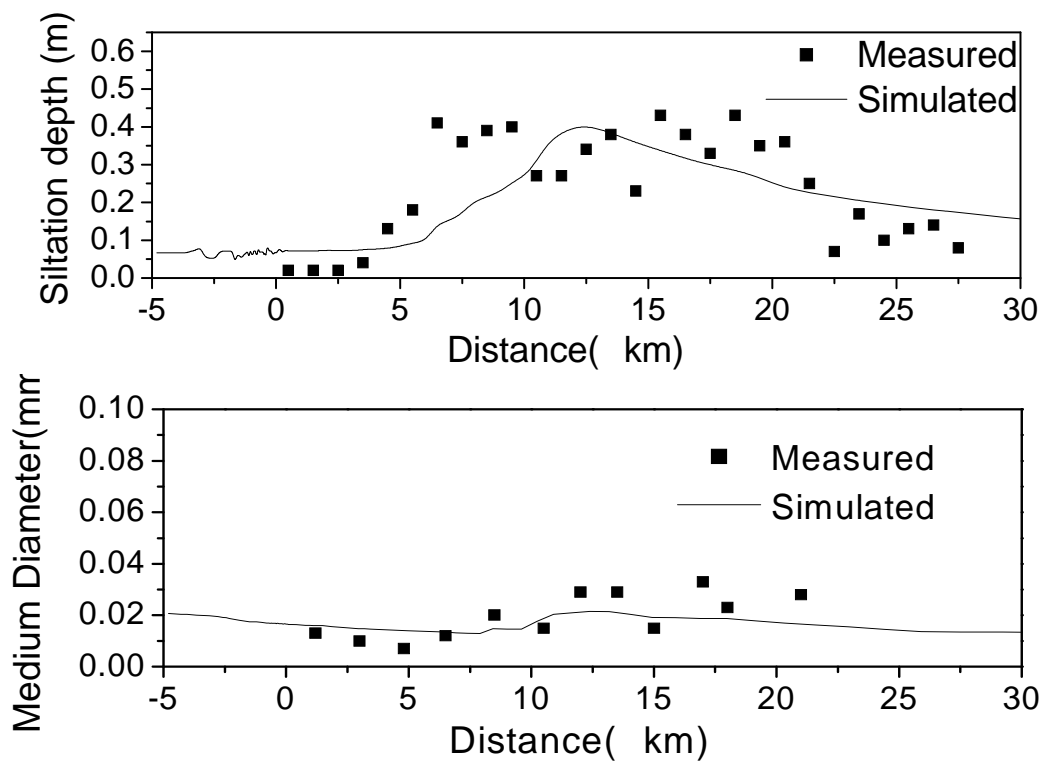

Figure 14. Calculated and measured siltation thickness and $d_{50}$ along channel in the storm event of March 10 , 2006. 


\section{CONCLUSION}

The sorting sedimentation and channel siltation in storm events were simulated by applying coupled models of EFDC and SWAN around Huanghua Harbor in Bohai Bay. The following conclusions are drawn:

1. The 3-D EFDC model was modified by incorporating the wave breaking effects in nearshore zones, and it is able to predict the sediment transport nearshore reasonable.

2. Wind waves were simulated by SWAN model.

3. Multi-class sediment was considered.

4. The simulated wave height, water level, siltation depth and variation of medium diameter for deposited sediment along the channel basically agreed with the measured data.

5. The high sediment concentration near sea bed for silty coast during storm processes was well simulated.

6. The deposited sediment in the entrance channel showed sorting sedimentation phenomenon during storm event.

\section{ACKNOWLEDGMENTS}

The research was supported by the Open Foundation of State Key Laboratory of Estuarine and Coastal Research, East China Normal University (Grant No. SKLEC200906) and by the Foundation for Innovative Research Groups of the National Natural Science Foundation of China (Grant no. 51021004).

\section{REFERENCES}

Booij, N.C., R.C. Ris, and L.H. Holthuijsen. 1999. A third-generation wave model for coastal regions: 1. Model description and validation, Journal of Geophysical Research, 104, 7649-7666.

Hamrick, J.M. 1992. A three-dimensional environmental fluid dynamics computer code: theoretical and computational aspects, Special Report, VIMS, Virginia, 317pp.

Han H.S., S.S. Li, and Q. Zhao. 2006. Experiment study of vertical distribution of suspended concentration for silt under breaking wave condition. Journal of Sediment Research, (6), 30-36. ( in Chinese).

Mellor G.L., and T. Yamada. 1982. Development of a turbulence closure model for geophysical fluid problems, Reviews of Geophysics and Space Physics, 20, 851-875.

van Rijn L.C., M. W. C. Nieuwjaar, T. van der Kaay, E. Nap and A. van Kampen. 1993. Transport of fine sands by currents and waves. Journal of Waterway, Port, Coastal and Ocean Engineering 119(2), 123-133.

van Rijn L.C. 2007. Unified View of Sediment Transport by Currents and Waves. II: Suspended Transport, Journal of Hydraulic Engineering, 133, 668-689.

Xu H.M., and Y.L. Feng. 1998. Study on sediment transport in Huanghua Port project, Journal of Sediment Research, (1), 20-29. (in Chinese).

Yan B. 2008. Study of Sediment Transport and Channel Siltation on Silty Coast, Ph.D. thesis, Tianjin University ( in Chinese).

Yan X.X. 2005. The sediment composition and distribution in nearshore zones of Huanghua Port, Journal of Waterway and Harbor, 26, 144-148. (in Chinese).

Zhang Q.H., F.L. Hou, B. Xia, J.F. Zhang, and H. Yan. 2006. Two dimensional numerical simulation of siltation in outer channel of Huanghua Harbor, China Harbor Engineering, 5, 6-9. (in Chinese)

Zhang Q.H., C.X. Wang, and H. Yang. 2004. The characteristics and affects of seabed surface sediment of Huanghua port, China Harbour Engineering, 4, 14-17. (in Chinese)

Zhao Q. 2006. Fine sediment transport in storm event-the Huanghua experience, Proceedings of $30^{\text {th }}$ International Conference on Coastal Engineering. ASCE, 2956-2968. 